\title{
Behaviour Setting dalam Sistem Keamanan Bangunan Sekolah Dasar
}

\author{
Yostia Muhaimi dan Bambang Soemardiono \\ Departemen Arsitektur, Fakultas Arsitektur Desain dan Perencanaan, Institut Teknologi Sepuluh \\ Nopember (ITS) \\ e-mail:bamsoe03@yahoo.com
}

\begin{abstract}
Abstrak-Unsur keamanan merupakan salah satu element penting dalam suatu perancangan suatu bangunan. Terlebih dalam bangunan publik yakni sekolah. Dalam sistem keamanan yang ada pertimbangan yang diambil kebanyakan memakai cara teknis, seperti teknologi CCTV, dll. Namun ternyata cara ini masih tergolong kurang dalam menanggulangi terjadinya tindak kriminal maupun memberikan perasaan nyaman kepada pengguna. Oleh karenanya diperlukan pertimbangan lain yang menunjang sistem keamanan yang ada. Seperti memasukkan unsur behavior setting dalam sistem yang ada. Behaviour setting merupakan konsep dimana sebuah ruangan terbentuk atas perilaku manusia. Behaviour setting digunakan sebagai alat analisis untuk sebuah desain agar desain tersebut sesuai dengan penggunanya. Dengan adanya behavior setting sistem keamanan yang ada lebih memberikan rasa aman dan juga nyaman bagi penggunanya. Karena sistem yang ada telah sesuai dengan kebutuhan pengguna tanpa memberikan rasa tidak nyaman.
\end{abstract}

Kata Kunci-Behaviour Setting, keamanan, kriminalitas, sekolah.

\section{PENDAHULUAN}

$\mathrm{A}$ RSITEKTUR hadir untuk memenuhi kebutuhan primer manusia akan kebutuhan papan. Dalam perancangannya arsitektur tidak hanya berkutat dengan unsur teknis yang kasat mata, namun dia juga memiliki pertimbangan-pertimbangan serius yang menyangkut pengguna bangunan itu maupun efek yang terjadi ketika akhirnya dibangun. Oleh karenanya arsitektur merupakan obyek yang sangat kompleks jika dipelajari karena didalamnya penuh dengan cerminan manusia atau pengguna di dalamnya bahkan pada lingkungan sekitarnya.

Arsitektur selalu memberikan dampak bagi penggunanya. Menurut Peter Zumthor di bukunya Thinking Architecture mengatakan bahwa arsitektur tidak lepas dari kehidupan manusia [1]. Mulai dari bangun tidur sampai tertidur kembali manusia selalu menjumpai arsitektur. Arsitektur memberikan kesan dan pengalaman kepada penggunanya. Pengalaman inilah yang membentuk suatu tindakan dan kebiasaan penggunanya. Karena itulah baik secara langsung maupun tidak arsitektur dapat mempengaruhi pola perilaku seseorang.

Setiap elemen yang ada di dalam perancangan sebuah obyek arsitektur kerap mempertimbangkan dampak penggunanya. Salah satunya adalah sistem keamanan bangunan. Namun sistem keamanan yang ada kebanyakan lebih condong ke penyelesaian teknis, seperti penggunaan

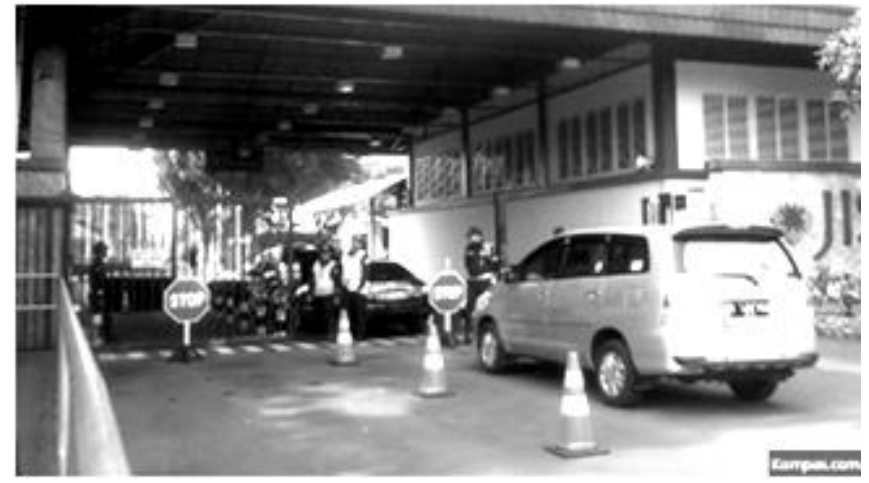

Gambar 1. Cont oh sistem keamanan pada umumnya. (sumber; kompas).

gerbang yang rapat atau penggunaan CCTV (Gambar 1). Sistem keamanan ini memang menjamin keamanan yang ada, namun penggalaman atau kesan yang timbul dalam penggunaanya menimbulkan 'rasa' yang tidak nyaman. Untuk itulah diperlukan sistem tambahan atau sistem lain yang dapat memberikan kenyamanan dan rasa aman yang tidak dapat dihadirkan dari sistem keamanan yang ada.

\section{PENDEKATAN DAN METODE RANCANG}

\section{A. Pendekatan}

Pendekatan yang digunakan dalam membentuk sistem keamanan yang baru adalah pendekatan behaviour setting. Behaviour setting adalah konsep dimana sebuah ruangan terbentuk dari perilaku manusia. Oleh karenanya ruangan yang terbentuk dapat mewadahi aktivitas penggunanya. Konsep ini menuntut agar desain mengikuti sifat manusia dalam beraktifitas.

Dalam behaviour setting terdapat aspek-aspek yang diamati diantaranya :

- pengguna

- karakteristik setting

- perilaku (stimulun, respon, dan adaptasi)

- pola aktivitas

\section{B. Metode rancang}

Metode rancang yang digunakan adalah Comprehensive anticipatory design science oleh Buckminster Fuller. Comprehensive berarti berhubungan dengan seluruh sistem, dunia, seluruh kemanusiaan dan seluruh variable penting yang mempengaruhi masalah dan kebutuhan bumi dan penghuninya. Anticipatory berarti persiapan untuk menghadapi krisis yang akan datang dari kejadiannya dan perbuatannya baik untuk kebutuhan kemanusiaan sekarang maupun di masa depan. Design adalah proses integrative sintesis dari bagian-bagian menjadi satu kesatuan. Science 
adalah logis, sistematis, dan metode penelitian dan mengorganis ir pengalaman.

Metode Comprehensive anticipatory design science muncul berdasarkan metode Design Science yang merupakan metode problem-solving.

Metode ini terdiri dari berbagai tahapan.(Gambar 2). Tahapan pertama isu yang ada difokuskan, dalam hal ini isu keamanan dan kenyaman menjadi fokus utama. Lalu pada tahapan kedua, akar dari permasalahan mulai dicari. Dalam tahapan ini ditemukan bahwa keamanan yang ada tidak atau kurang memberikan rasa nyaman bagi penggunanya.

Kemudian pada tahapan ketiga adalah tahapan dimana tujuan diutarakan. Dalam tahapan ini terdapat analisa dari preseden dengan menggunakan behavior setting. Preseden yang dianalisa adalah bangunan Utase Elementary School yang dibangun oleh sebuah firma di Jepang C+A atau Coelacanth and Associates Tokyo. (Gambar 3 ). Bangunan ini dipilih berdasarkan konsep akan kemanan yang diberikan. Konsep desain dari bangunan ini adalah openness, dimana bangunan tidak memiliki batas fisik yang benar-benar menutupi bangunan secara visual baik di dalam maupun di luar bangunan. (Gambar 4)

Kemudian tahapan selanjutnya adalah tahapan dimana kondisi yang ada dianalisa lebih lanjut, guna dibandingkan dengan hasil analisa dari tahapan sebelumnya. Lalu dari perbandingan hasil analisa kedua tahapan tersebut dapat menghasilkan kriteria yang akan digunakan sebagaibahan

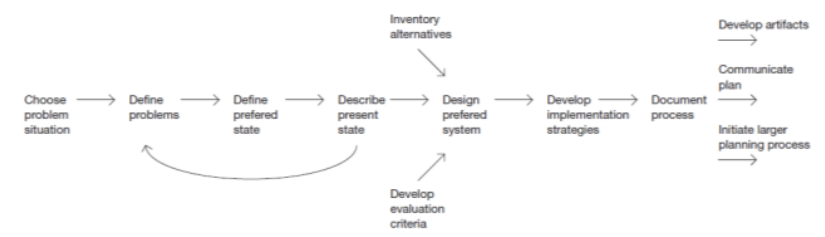

Gambar 2. Diagram Metode Comprehensive anticipatory design science.
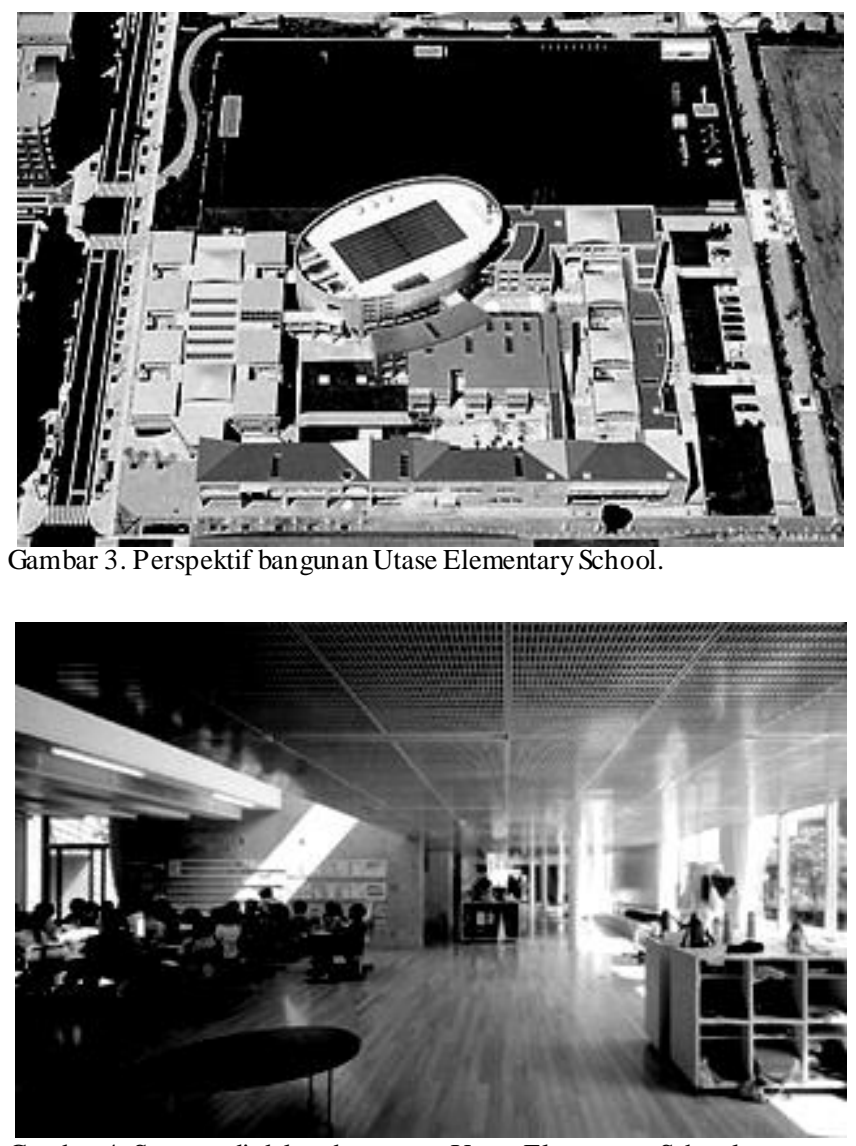

Gambar 4. Suasana di dalam bangunan Utase Elementary School. pertimbangan pembuatan konsep-konsep yang muncul. Setelah itu, tahapan yang ada yakni membuat konsep berdasarkan hasil analisa yang ada beserta dimana konsep itu dapat diimplementasikan dalam desain.

\section{EKSPLORASI DAN HASIL}

\section{A. Eksplorasi Formal}

Konsep yang ada lahir dari metode Comprehensive anticipatory design science oleh Buckminster Fuller dan pendekatan behavior setting. Konsep utama yang muncul adalah konsep openness. Maksudnya adalah Bangunan yang ada tidak memiliki batas visual. Hal ini didapatkan dari kelemahan batas yang ada pada umumnya menimbulakn kesan mengekang dan memiliki sudut buta yang tidak terawasi. Dengan konsep ini, bangunan mudah diakses sampai batas tertentu dan masih dapat terlihat sehingga ketika terjadi kejadian yang tidak diinginkan hal itu terawasi. Dari kriteria yang telah disebutkan, dapat dijabarkan menjadi beberapa konsep dapat dilihat pada Tabel 1.

Tabel 1.

Penjabaran Konsep

\begin{tabular}{|c|c|c|}
\hline " KRITERIA & & $\overline{\mathrm{KONSEP}}$ \\
\hline \multirow{4}{*}{$\begin{array}{l}\text { Open to the } \\
\text { environment }\end{array}$} & $\begin{array}{l}\text { Ruangan yang memerlukan } \\
\text { pengawasan tidak mempunyai } \\
\text { dinding at au berdinding }\end{array}$ & Konsep ruang \\
\hline & $\begin{array}{c}\text { transparent } \\
\text { Jarak antar bangunan dan jalur } \\
\text { sirkulasi cukup lebar }\end{array}$ & Konsep tapak \\
\hline & $\begin{array}{l}\text { Menghindari terbentuknya } \\
\text { lorong kecil diantara dua } \\
\text { bangunan }\end{array}$ & Konsep tapak \\
\hline & $\begin{array}{l}\text { Terdapat fasilitas bersama yang } \\
\text { terletak dekat dengan warga }\end{array}$ & Konsep tapak \\
\hline \multirow[t]{2}{*}{$\begin{array}{l}\text { Open to the } \\
\text { society }\end{array}$} & $\begin{array}{c}\text { Tidak terdapat pagaryang } \\
\text { membatasi antara areabangunan } \\
\text { dengan penduduk (Gambar } 8 \text { ) }\end{array}$ & $\begin{array}{l}\text { Konsep tapak, } \\
\text { bentuk }\end{array}$ \\
\hline & $\begin{array}{l}\text { Area kelas dekat dengan area } \\
\text { pemukiman penduduk }\end{array}$ & Konsep T apak \\
\hline \multirow[t]{2}{*}{$\begin{array}{l}\text { Centralized } \\
\text { secure area }\end{array}$} & $\begin{array}{l}\text { Memusatkan area yang } \\
\text { memerlukan pengawasan tinggi }\end{array}$ & Konsep tapak \\
\hline & Ruang kelas berwarna-warni & Konsep ruang \\
\hline Create & $\begin{array}{c}\text { Terdapat ruang belajar di luar } \\
\text { ruangan }\end{array}$ & Konsep tapak \\
\hline $\begin{array}{l}\text { learning } \\
\text { atmosphere }\end{array}$ & $\begin{array}{c}\text { Di sepanjang koridor terdapat } \\
\text { tempat-tempat duduk yang dapat } \\
\text { dimanfaatkan untuk berkumpul } \\
\text { dan berdiskusi }\end{array}$ & Konsep ruang \\
\hline
\end{tabular}

B. Eksplorasi Teknis.

1) Konsep Ruang

\section{a. Konsep dinding}

Ruang kelas didesain dengan tidak menggunakan dinding massif. Hal ini supaya mempermudah pengawasan dalam setiap kegiatan di dalam kelas. Dinding yang ada berupa dinding partisi atau bermaterial transparan.(Gambar 5) Untuk dinding wc terdiri dari dinding partisi dan dinding kaca yang disesuaikan dengan tinggi pengguna sehingga WC tetap terawasi namun tetap privat. Selain itu dinding WC terdiri dari dinding partisi dan dinding kaca. Dinding yang tidak visible setinggi pengguna, sehingga wc tetap privat Sedangkan dinding visible (kaca) digunakan pada dinding bagian bawah dengan ketinggian tertentu yang 
digunakan sebagai lubang intip yang berfungsi sebagai pengawas an dapat dilihat pada Gambar 5.

\section{b. Konsep bentuk ruang}

Bentuk ruangan yang ada dibagi menjadi dua, yakni bentuk dengan garis lengkung dan ruangan dengan garis lurus atau kaku. Kedua bentuk ini didapat berdasarkan kegiatan apa yang akan terjadi nantinya. Bentukan dengan garis lengkung memiliki lebih banyak stimulan dibandingkan garis lurus. Bentuk ini dapat diterapkan di ruang santai atau taman untuk mengalihkan perhatian anak atau tetap membuat anak fokus kepada suatu hal. Sedangkan bentukan dengan garis lurus memiliki sedikit stimulan. Ruang dengan bentuk dengan garis lurus memiliki sedikit stimulan. Hal ini cocok untuk ruangan yang membutuhkan sedikit stimulan luar seperti kelas. Ruang kelas hendaknya memiliki suasana yang dapat memudahkan anak untuk lebih fokus kepada situasi di dalam kelas dapat dilihat pada Gambar 6

\section{2) Konsep Tata Tapak}

Tata tapak timbul akibat dari adanya kegiatan yang berlangsung di dalam tapak. Letak dari setiap ruang mengikuti gerakan dari kegiatan yang ada dapat dilihat pada Gambar 7. Dari diagram pergerakan tersebut, organisasi ruang dapat ditentukan yang kemudian memberikan gambaran letak dari setiap ruang yang ada.Kemudian dari tiap ruangan dibentuk sesuai dengan konsep bentuk ruang dapat dilihat pada Gambar 6. Selain itu batas bangunan yang ada berupa taman dan kolam yang berada di sebelah timur bangunan, kolam dan pagar kayu di bagian selatan dan tumbuhan disebelah barat dapat dilihat pada Gambar 8 . Batas-batas ini tidak menghalangi view dari dan ke bangunan dapat dilihat pada Gambar 9 .

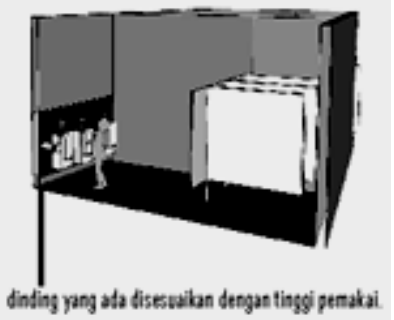

Gambar 5. Bentuk ruang WC.

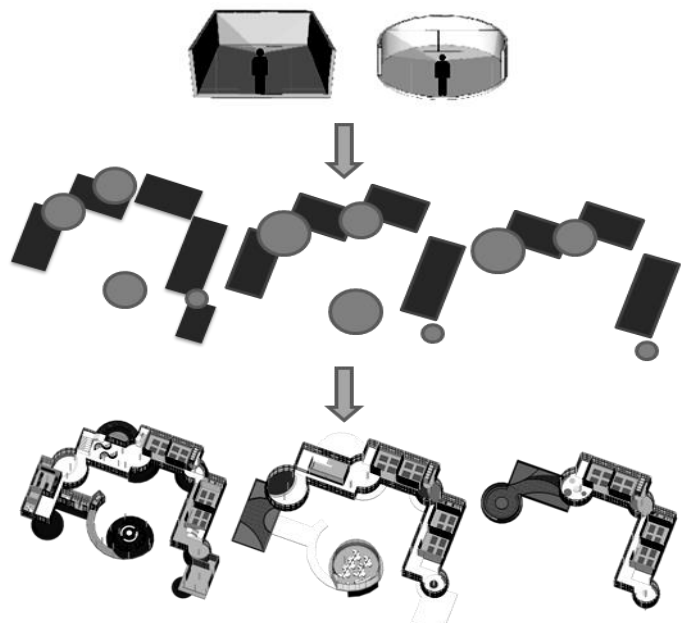

Gambar 6. Konsep benuk ruang.

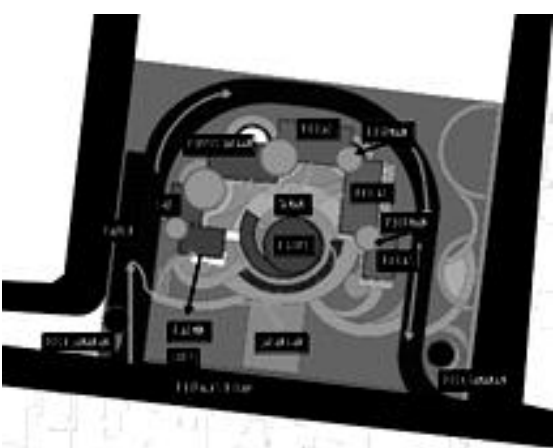

Gambar 7. Diagram pergerakan bangunan.

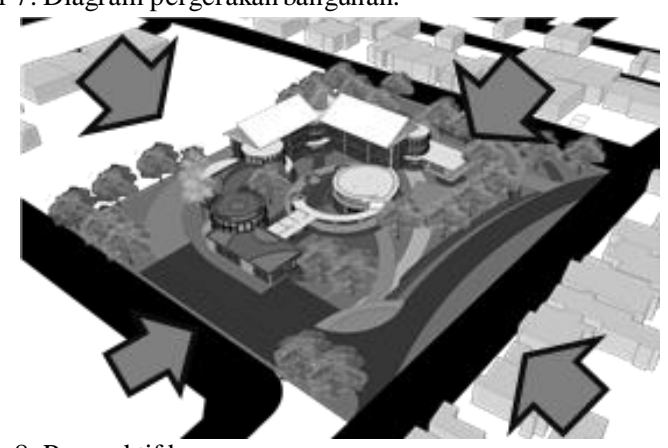

Gambar 8. Perspektif bangunan.
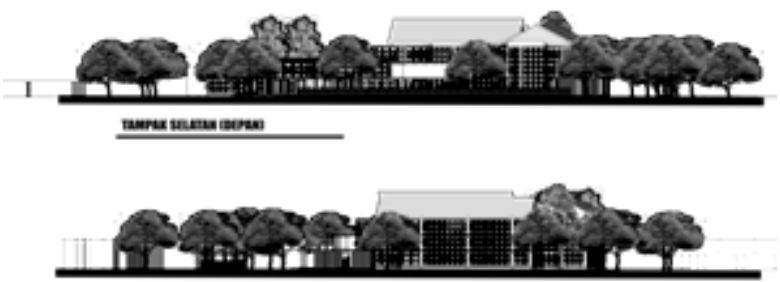

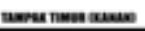

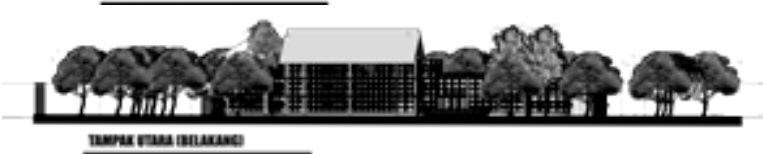

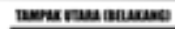

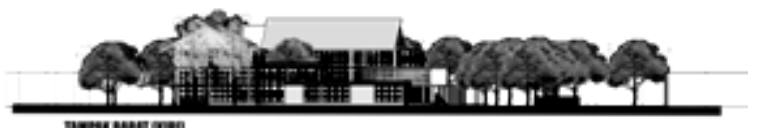

Gambar 9. Tampak bangunan.

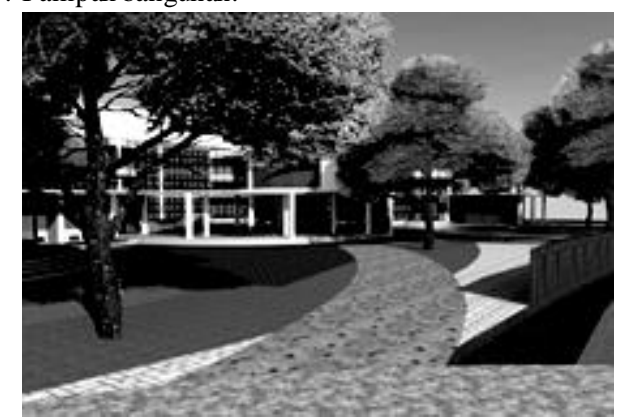

Gambar 10. Perspektif titik drop off.

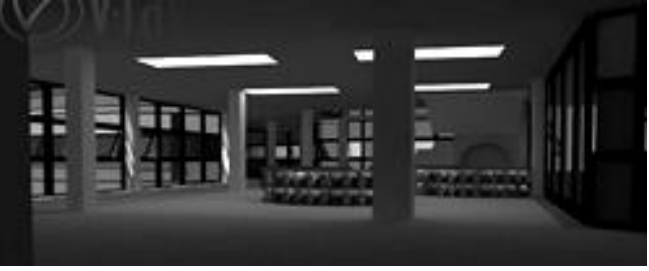

Gambar 11. Suasana ruang perpustakaan dan koridor. 


\section{KESIMPULAN}

Behaviour setting dalam perancangan sebuah sistem digunakan sebagai alat ukur atau analisa suatu desain. Ketika behavior setting dimasukkan kedalam sistem keamanan yang ada, sistem keamanan menjadi lebih mudah diterima atau nyaman bagi penggunanya karena sesuai dengan pola perilaku yang ada.

\section{DAFTAR PUSTAKA}

[1] P. Zumthor, Thinking Architecture. Basel: Birkhäuser Architecture, 1998. 